\title{
Ethnicity in relation to incidence of oesophageal and gastric cancer in England
}

\author{
VH Coupland",', J Lagergren ${ }^{2,3}$, J Konfortion', W Allum4, MA Mendall', RH Hardwick', KM Linklater', H Møller' \\ and RH Jack'
}

'King's College London, Thames Cancer Registry, Ist Floor Capital House, 42, Weston Street, London SEI 3QD, UK; '2Division of Cancer Studies, King's College London, London, UK; ${ }^{3}$ Karolinska Institutet, Unit of Upper Gastrointestinal Research, Norra Stationsgatan 67, Level 2, Stockholm I 7 I 76, Sweden; ${ }^{4}$ Department of Surgery, Royal Marsden NHS Foundation Trust, London SW3 6JJ, UK; ${ }^{5}$ Department of Gastroenterology, Mayday University Hospital, Croydon, UK; ${ }^{6}$ Cambridge Oesophago-Gastric Centre, Addenbrookes Hospital, PO Box 201, Hills Road, Cambridge CB2 2QQ, UK

BACKGROUND: This study investigated the variation in incidence of all, and six subgroups of, oesophageal and gastric cancer between ethnic groups.

METHODS: Data on all oesophageal and gastric cancer patients diagnosed between $200 \mathrm{I}$ and 2007 in England were analysed. Selfassigned ethnicity from the Hospital Episode Statistics dataset was used. Male and female age-standardised incidence rate ratios (IRRs) were calculated for each ethnic group, using White groups as the references.

RESULTS: Ethnicity information was available for $83 \%$ of patients (76 130/92 205). White men had a higher incidence of oesophageal cancer, with IRR for the other ethnic groups ranging from $0.1795 \%$ confidence interval (CI) (0.15-0.20) (Pakistani men) to $0.5895 \%$ Cl (0.50-0.67) (Black Caribbean men). Compared with White women, Bangladeshi women (IRR 2.02 (I.24-3.29)) had a higher incidence of oesophageal cancer. For gastric cancer, Black Caribbean men (1.39 (1.22-1.60)) and women (1.57 (1.28-1.92)) had a higher incidence compared with their White counterparts. In the subgroup analysis, White men had a higher incidence of lower oesophageal and gastric cardia cancer compared with the other ethnic groups studied. Bangladeshi women (3.10 (1.60-6.00)) had a higher incidence of upper and middle oesophageal cancer compared with White women.

CONCLUSION: Substantial ethnic differences in the incidence of oesophageal and gastric cancer were found. Further research into differences in exposures to risk factors between ethnic groups could elucidate why the observed variation in incidence exists.

British Journal of Cancer (2012) 107, 1908-1914. doi:I0.1038/bjc.2012.465 www.bjcancer.com

Published online II October 2012

(c) 2012 Cancer Research UK

Keywords: oesophageal cancer; gastric cancer; ethnicity; incidence

Internationally there is wide variation in the incidence of oesophageal and gastric cancers (Curado et al, 2007). Variation in the incidence of these cancers has also been reported between ethnic groups within countries (Curado et al, 2007; Goggins and Wong, 2009; National Cancer Intelligence Network, 2009; Ali et al, 2010). A large English study found a lower incidence of oesophageal cancer in South Asian (including Indian, Pakistani, and Bangladeshi groups) and Black men and women compared with White men and women (National Cancer Intelligence Network, 2009). The same report found South Asian men and women had a lower incidence of gastric cancer, and Black men and women a higher incidence compared with their White counterparts (National Cancer Intelligence Network, 2009).

Oesophageal and gastric cancer subgroups display different epidemiological patterns and are associated with different risk factors (Blot et al, 2006; Crew and Neugut, 2006; Coupland et al, 2012). Several studies in the United States and one in the United Kingdom found that the incidence of oesophageal squamous cell carcinoma was higher in Black men compared with White men,

*Correspondence: VH Coupland; E-mail: victoria.coupland@kcl.ac.uk Revised 4 September 2012; accepted 18 September 2012; published online 11 October 2012 whereas oesophageal adenocarcinoma was found to be higher in White men (Yang and Davis, 1988b; Corley and Buffler, 2001; El-Serag et al, 2002; Vizcaino et al, 2002; Kubo and Corley, 2004; Wu et al, 2006; Curado et al, 2007; Cook et al, 2009; Cooper et al, 2009; Hongo et al, 2009). Although the incidence of gastric cardia cancer is higher in White men (Yang and Davis, 1988a; Corley and Buffler, 2001; El-Serag et al, 2002; Kubo and Corley, 2004; $\mathrm{Wu}$ et $\mathrm{al}, 2006,2009)$, the incidence of gastric non-cardia cancer has been found to be higher in Black men and women compared with their White counterparts (Yang and Davis, 1988a; Wu et al, 2006, 2009).

A recent national English study investigated differences in the incidence of oesophageal and gastric cancer using broad ethnic groups (National Cancer Intelligence Network, 2009). To date, the majority of studies investigating the variation in incidence between ethnic groups for the more specific subgroups of these cancers have occurred in the United States. This study aimed to assess the variation in incidence in more specific ethnic groups (White, Indian, Pakistani, Bangladeshi, Black Caribbean, Black African, and Chinese) and for six subgroups (upper and middle oesophagus, lower oesophagus, oesophagus not otherwise specified, gastric cardia, gastric non-cardia, and gastric not otherwise specified) of oesophageal and gastric cancer in England. 


\section{MATERIALS AND METHODS}

\section{Study population}

Data on 44307 patients diagnosed with oesophageal cancer (ICD10 C15) and 47898 patients diagnosed with gastric cancer (ICD10 C16) in England between 2001 and 2007 were extracted from the National Cancer Data Repository (NCDR). The NCDR contains information collected by the eight English cancer registries on all cancer patients diagnosed in their catchment areas. These data are quality assured in each registry before being combined into the English dataset (National Cancer Intelligence Network, 2011).

Ethnicity was classified using the most recent valid self-assigned ethnicity code from the Hospital Episode Statistics (HES) dataset. Ethnic groups were analysed for seven categories: White, Indian, Pakistani, Bangladeshi, Black Caribbean, Black African, and Chinese. The corresponding population data for each age and ethnic group were obtained from the Office for National Statistics with 2001 populations taken from the census year and combined with the mid-year population estimates between 2002 and 2007 (Office for National Statistics, 2011).

Analysis was carried out on all oesophageal and gastric cancer cases and for six subgroups of these cancers: (1) upper and middle oesophagus, (2) lower oesophagus, (3) oesophagus with an unspecified anatomical site (oesophageal not otherwise specified (NOS)), (4) gastric cardia, (5) gastric non-cardia, and (6) gastric with an unspecified anatomical site (gastric NOS). These groups were defined primarily on the basis of ICD10 codes (Table 1). However, to ensure maximum use of the available coding, we reassigned patients in the oesophageal NOS group who had a histological diagnosis of adenocarcinoma into the lower oesophageal group and those with oesophageal NOS cancer and squamous cell carcinoma into the upper and middle oesophageal group. This was because the vast majority of oesophageal adenocarcinomas occur in the lower third of the oesophagus (Department of Health, 2001; Pohl and Welch, 2005), whereas squamous cell carcinoma is more evenly distributed throughout the entire length of the oesophagus (Department of Health, 2001). A sensitivity analysis was also carried out defining the oesophageal subgroups based on only their histological diagnosis. Three groups were analysed: squamous cell carcinoma, adenocarcinoma, and 'other and unspecified'.

\section{Statistical analysis}

Age-standardised incidence rates per 100000 European standard population were calculated for all males and females diagnosed with oesophageal and gastric cancer and for the six cancer subgroups. This was then repeated for each ethnic group. As not all patients had an ethnic group recorded, any age-standardised incidence rates calculated would be too low, as there was no corresponding population data for these patients. Therefore, male and female age-standardised incidence rate ratios (IRRs) were calculated for each ethnic group, using White males and White females as the references. 95\% confidence intervals (CIs) were calculated using the method described in Boyle and Parkin, 1991.

\section{RESULTS}

\section{Patients}

There were 92205 oesophageal and gastric cancer patients diagnosed in England between 2001 and 2007. Ethnicity information was available for $76130(82.6 \%)$ of the 92205 patients. The White, Indian, Pakistani, Bangladeshi, Black Caribbean, Black African, and Chinese groups made up $98.8 \%$ of those with a recorded ethnicity (75180 of 76130 ). Table 2 shows the number and proportion of patients in each ethnic group for each cancer type and subgroup. The incidence of oesophageal and gastric cancer was higher in males (14.0 and 14.7, respectively) compared with females (5.6 and 5.9, respectively). This was particularly the case in lower oesophageal and gastric cardia cancer with males having incidence rates around four times higher than females.

\section{Ethnicity and risk of oesophageal cancer}

Compared with White men, Indian (IRR 0.42, 95\% CI 0.37-0.46), Pakistani (IRR 0.17, 95\% CI 0.15-0.20), Bangladeshi (IRR 0.39, 95\% CI 0.29-0.53), Black Caribbean (IRR 0.58, 95\% CI 0.50-0.67), Black African (IRR 0.39, 95\% CI 0.31-0.50), and Chinese (IRR 0.36, 95\% CI 0.27-0.47) men had a lower incidence of oesophageal cancer (Figure 1). Compared with White women, Bangladeshi women (IRR 2.02, 95\% CI 1.24-3.29) had a higher incidence of oesophageal cancer and Black African women (IRR 0.86, 95\% CI 0.57-1.30) had a similar incidence, whereas Indian (IRR 0.68, 95\% CI 0.57-0.81), Pakistani (IRR 0.26, 95\% CI 0.20-0.33), Black Caribbean (IRR 0.56, 95\% CI 0.46-0.69), and Chinese (IRR 0.42, 95\% CI 0.28-0.62) women had a lower incidence (Figure 1).

\section{Ethnicity and risk of gastric cancer}

Indian (IRR 0.41, 95\% CI 0.37-0.45), Pakistani (IRR 0.47, 95\% CI 0.40-0.55), and Bangladeshi (IRR 0.62, 95\% CI 0.47-0.82) men had a lower incidence of gastric cancer compared with White men. Black Caribbean men had a higher incidence (IRR 1.39, 95\% CI 1.22-1.60) and Black African (IRR 1.04, 95\% CI 0.80-1.35) and Chinese (IRR $0.99,95 \%$ CI $0.75-1.31$ ) men had a similar incidence to White men (Figure 2). Compared with White women, Indian (IRR 0.57, 95\% CI 0.48-0.67) and Pakistani (IRR 0.71, 95\% CI 0.540.93) women had a lower incidence of gastric cancer, Black

Table I Oesophageal and gastric cancer group definitions

\begin{tabular}{|c|c|}
\hline $\begin{array}{l}\text { Oesophageal and gastric } \\
\text { cancer groups }\end{array}$ & $\begin{array}{l}\text { International classification of diseases version } 10 \text { (ICDI0) and international } \\
\text { classification of diseases for oncology version } 2 \text { (ICDO2) codes }\end{array}$ \\
\hline Oesophagus & $\mathrm{Cl} 5$ \\
\hline Upper and middle oesophagus & $\begin{array}{l}\text { CI5.0-CI5.I, CI5.3-CI5.4 } \\
\text { including CI5.8-CI5.9 with a morphology code } 8050-8083 \text { (squamous cell carcinomas) }\end{array}$ \\
\hline Lower oesophagus & $\begin{array}{l}\text { CI5.2, CI5.5 } \\
\text { including CI5.8-CI5.9 with a morphology code } 8140-8576 \text { (adenocarcinomas) }\end{array}$ \\
\hline Oesophagus not otherwise specified & $\begin{array}{l}\text { CI5.8-CI5.9 } \\
\text { excluding CI5.8-CI5.9 with a morphology code } 8050-8083 \text { (squamous cell carcinomas) or } 8140-8576 \text { (adenocarcinomas) }\end{array}$ \\
\hline Gastric & $\mathrm{Cl} 6$ \\
\hline Gastric cardia & $\mathrm{Cl} 6.0$ \\
\hline Gastric non-cardia & $\mathrm{Cl} 6.1-\mathrm{Cl} 6.6$ \\
\hline Gastric not otherwise specified & $\mathrm{Cl} 6.8-\mathrm{Cl} 6.9$ \\
\hline
\end{tabular}


Table 2 Number and percentage of males and females in each ethnic group for patients diagnosed with oesophageal cancer or gastric cancer in England between 2001 and 2007, by sex and subgroup

\begin{tabular}{|c|c|c|c|c|c|c|c|c|c|c|c|c|c|c|c|c|c|c|}
\hline \multirow{3}{*}{$\begin{array}{l}\text { Total } \\
\text { Ethnic group }\end{array}$} & \multirow{2}{*}{\multicolumn{2}{|c|}{$\begin{array}{c}\text { Oesophagus } \\
44307\end{array}$}} & \multirow{2}{*}{\multicolumn{2}{|c|}{$\begin{array}{l}\text { Upper and } \\
\text { middle } \\
\text { oesophagus } \\
\text { I } 2872\end{array}$}} & \multirow{2}{*}{\multicolumn{2}{|c|}{$\begin{array}{c}\text { Lower } \\
\text { oesophagus } \\
26299\end{array}$}} & \multirow{2}{*}{\multicolumn{2}{|c|}{$\begin{array}{c}\text { Oesophagus } \\
\text { NOS } \\
5136\end{array}$}} & \multirow{2}{*}{\multicolumn{2}{|c|}{$\begin{array}{c}\text { Gastric } \\
47898\end{array}$}} & \multirow{2}{*}{\multicolumn{2}{|c|}{$\begin{array}{l}\text { Gastric } \\
\text { cardia } \\
12672\end{array}$}} & \multirow{2}{*}{\multicolumn{2}{|c|}{$\begin{array}{c}\text { Gastric } \\
\text { non-cardia } \\
10373\end{array}$}} & \multirow{2}{*}{\multicolumn{2}{|c|}{$\begin{array}{c}\text { Gastric } \\
\text { NOS } \\
24853\end{array}$}} & \multirow{2}{*}{\multicolumn{2}{|c|}{$\begin{array}{c}\text { Oesophageal } \\
\text { and gastric } \\
\text { cancer } \\
92205\end{array}$}} \\
\hline & & & & & & & & & & & & & & & & & & \\
\hline & $\mathbf{N}$ & $\%$ & $\mathbf{N}$ & $\%$ & $\mathbf{N}$ & $\%$ & $\mathbf{N}$ & $\%$ & $\mathbf{N}$ & $\%$ & $\mathbf{N}$ & $\%$ & $\mathbf{N}$ & $\%$ & $\mathbf{N}$ & $\%$ & $N$ & $\%$ \\
\hline \multicolumn{19}{|l|}{ Males } \\
\hline White & 23603 & 83.1 & 4875 & 82.8 & 16797 & 85.5 & 1931 & 67.1 & 24509 & 79.4 & 8145 & 85.6 & 5294 & 82.2 & | | 070 & 74.2 & $48 \mid 12$ & 81.1 \\
\hline Indian & 138 & 0.5 & 64 & 1.1 & 57 & 0.3 & 17 & 0.6 & $|4|$ & 0.5 & 21 & 0.2 & 32 & 0.5 & 88 & 0.6 & 279 & 0.5 \\
\hline Pakistani & 25 & 0.1 & 8 & 0.1 & 16 & 0.1 & I & $<0.1$ & 81 & 0.3 & 13 & 0.1 & 26 & 0.4 & 42 & 0.3 & 106 & 0.2 \\
\hline Bangladeshi & 22 & 0.1 & 12 & 0.2 & 7 & $<0.1$ & 3 & 0.1 & 37 & 0.1 & 3 & $<0.1$ & 9 & 0.1 & 25 & 0.2 & 59 & 0.1 \\
\hline Black Caribbean & 132 & 0.5 & 71 & 1.2 & 42 & 0.2 & 19 & 0.7 & 332 & l. 1 & 40 & 0.4 & 94 & 1.5 & 198 & 1.3 & 464 & 0.8 \\
\hline Black African & 33 & 0.1 & 11 & 0.2 & 18 & 0.1 & 4 & 0.1 & 76 & 0.2 & 10 & 0.1 & 18 & 0.3 & 48 & 0.3 & 109 & 0.2 \\
\hline Chinese & 22 & 0.1 & 14 & 0.2 & 4 & $<0.1$ & 4 & 0.1 & 60 & 0.2 & 3 & $<0.1$ & 17 & 0.3 & 40 & 0.3 & 82 & 0.1 \\
\hline Mixed & 37 & 0.1 & 10 & 0.2 & 25 & 0.1 & 2 & 0.1 & 73 & 0.2 & 14 & 0.1 & 14 & 0.2 & 45 & 0.3 & 110 & 0.2 \\
\hline Other & 193 & 0.7 & 60 & 1.0 & 110 & 0.6 & 23 & 0.8 & 313 & 1.0 & 55 & 0.6 & 71 & 1.1 & 187 & 1.3 & 506 & 0.9 \\
\hline Not known & 4214 & 14.8 & 765 & 13.0 & 2576 & 13.1 & 873 & 30.3 & 5257 & 17.0 & 1214 & 12.8 & 862 & 13.4 & 3181 & 21.3 & 947I & 16.0 \\
\hline All & 28419 & & 5890 & & 19652 & & 2877 & & 30879 & & 9518 & & 6437 & & 14924 & & 59298 & \\
\hline \multicolumn{19}{|l|}{ Females } \\
\hline White & 12683 & 79.8 & 5729 & 82.1 & 5535 & 83.3 & 1419 & 62.8 & 12687 & 74.5 & 2617 & 83.0 & 3147 & 80.0 & 6923 & 69.7 & 25370 & 77.1 \\
\hline Indian & 91 & 0.6 & 71 & 1.0 & 13 & 0.2 & 7 & 0.3 & 81 & 0.5 & 6 & 0.2 & 19 & 0.5 & 56 & 0.6 & 172 & 0.5 \\
\hline Pakistani & 15 & 0.1 & 12 & 0.2 & 3 & $<0.1$ & 0 & 0.0 & 43 & 0.3 & 5 & 0.2 & 10 & 0.3 & 28 & 0.3 & 58 & 0.2 \\
\hline Bangladeshi & 34 & 0.2 & 26 & 0.4 & 6 & 0.1 & 2 & 0.1 & 21 & 0.1 & 2 & 0.1 & 5 & 0.1 & 14 & 0.1 & 55 & 0.2 \\
\hline Black Caribbean & 56 & 0.4 & 36 & 0.5 & 15 & 0.2 & 5 & 0.2 & 153 & 0.9 & 15 & 0.5 & 27 & 0.7 & 111 & l. 1 & 209 & 0.6 \\
\hline Black African & 22 & 0.1 & 15 & 0.2 & 4 & 0.1 & 3 & 0.1 & 44 & 0.3 & 5 & 0.2 & 8 & 0.2 & 31 & 0.3 & 66 & 0.2 \\
\hline Chinese & 10 & 0.1 & 4 & 0.1 & 4 & 0.1 & 2 & 0.1 & 29 & 0.2 & 5 & 0.2 & 9 & 0.2 & 15 & 0.2 & 39 & 0.1 \\
\hline Mixed & 17 & 0.1 & 10 & 0.1 & 5 & 0.1 & 2 & 0.1 & 35 & 0.2 & 7 & 0.2 & 10 & 0.3 & 18 & 0.2 & 52 & 0.2 \\
\hline Other & 115 & 0.7 & 57 & 0.8 & 42 & 0.6 & 16 & 0.7 & 167 & 1.0 & 19 & 0.6 & 40 & 1.0 & 108 & I.1 & 282 & 0.9 \\
\hline Not known & 2845 & 17.9 & 1022 & 14.6 & 1020 & 15.3 & 803 & 35.5 & 3759 & 22.1 & 473 & 15.0 & 661 & 16.8 & 2625 & 26.4 & 6604 & 20.1 \\
\hline All & 15888 & & 6982 & & 6647 & & 2259 & & 17019 & & 3154 & & 3936 & & 9929 & & 32907 & \\
\hline
\end{tabular}

Caribbean (IRR 1.57, 95\% CI 1.28-1.92) women had a higher incidence and Bangladeshi, Black African, and Chinese women had a similar incidence (Figure 2).

\section{Ethnicity and risk of oesophageal cancer by subgroup}

Bangladeshi women had a higher incidence of upper and middle oesophageal cancer (IRR 3.10, 95\% CI 1.60-6.00), whereas Pakistani men (IRR 0.22 , 95\% CI 0.16-0.31) and Chinese women (IRR 0.34, 95\% CI 0.19-0.59) had a lower incidence compared with their White counterparts. White men had a higher incidence of lower oesophageal cancer compared with all other ethnic groups studied (Figure 3). Compared with White women, the incidence of lower oesophageal cancer was lower in all ethnic groups except Bangladeshi women who had a similar incidence (IRR 0.89, 95\% CI $0.40-2.00)$. There were a small number of cases of oesophageal NOS cancer in most ethnic groups studied (Table 2).

A sensitivity analysis found that the lower oesophageal and adenocarcinoma subgroups, the upper and middle oesophageal and squamous cell carcinoma subgroups, and the oesophageal NOS and 'other and unspecified' subgroups had similar patterns in incidence between ethnic groups.

\section{Ethnicity and risk of gastric cancer by subgroup}

White men had a higher incidence of gastric cardia cancer than other ethnic groups studied (Figure 3). Indian (IRR 0.20, 95\% CI $0.14-0.27$ ), Pakistani (IRR 0.46, 95\% CI 0.26-0.83), and Bangladeshi (IRR 0.25, 95\% CI 0.12-0.51) women had a lower incidence of this cancer compared with White women, while Black Caribbean, Black African, and Chinese women had a similar incidence. Compared with White men and women, Indian men (IRR 0.43, 95\% CI 0.34-0.54) and women (IRR 0.53, 95\% CI 0.38-0.74) and Pakistani men (IRR 0.66, 95\% CI 0.48-0.92) had a lower incidence of gastric non-cardia cancer and of gastric NOS cancer (IRR 0.59, 95\% CI $0.50-0.69$, IRR $0.74,95 \%$ CI $0.58-0.93$, and IRR $0.56,95 \%$ CI 0.44-0.70, respectively). Compared with their White counterparts, Black Caribbean men (IRR 1.81, 95\% CI 1.36-2.42) had a higher incidence of gastric non-cardia cancer. Black Caribbean men (IRR 1.94, 95\% CI 1.58-2.38) and women (IRR 2.11, 95\% CI 1.60-2.78), and Black African men (IRR 1.66, 95\% CI 1.10-2.49) and Chinese men (IRR 1.53, 95\% CI 1.01-2.31) had a higher incidence of gastric NOS cancer. All other groups had a similar incidence compared with their White counterparts.

\section{DISCUSSION}

A previous large English study found a lower incidence of oesophageal cancer in South Asian and Black men and women compared with White men and women (National Cancer Intelligence Network, 2009). In general our study supports these findings, but also demonstrates some variations between the more specific ethnic groups. For example, whereas Indian and Pakistani women had a lower incidence of oesophageal cancer, Bangladeshi women had a higher incidence compared with White women. The same report found that South Asian men and women had a lower incidence of gastric cancer, and Black men and women had a higher incidence compared with their White counterparts (National Cancer Intelligence Network, 2009). Again, our study largely supports the finding of lower incidence in the South Asian ethnic groups, except for Bangladeshi women who were found to have a similar incidence to White women. However, the higher incidence of gastric cancer found in Black individuals is driven by the larger Black Caribbean group.

Variation in incidence between ethnic groups in subgroups of oesophageal and gastric cancers has previously been reported. Studies in the United States have found the incidence of 


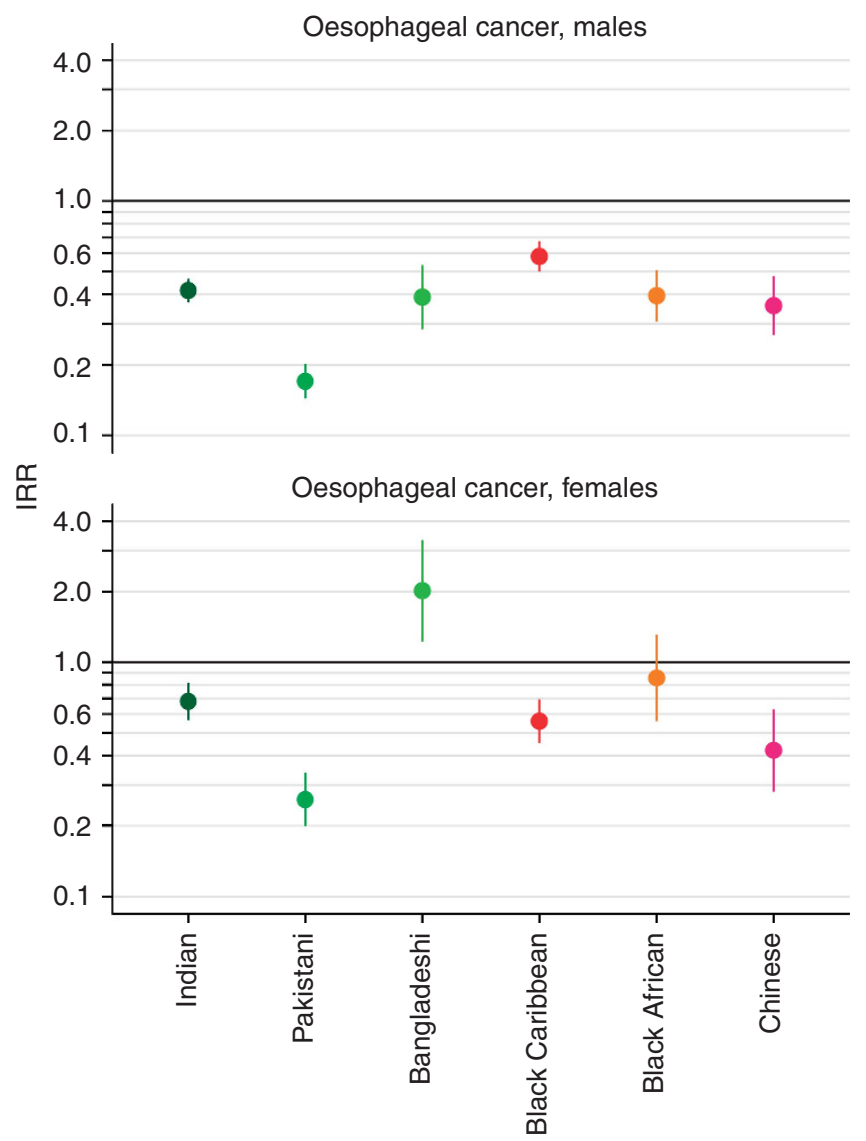

Figure I Age-standardised IRRs for men and women diagnosed with oesophageal cancer in England between 2001 and 2007 by ethnic group. White men and women used as references.

oesophageal squamous cell carcinoma to be up to six times higher in Black men compared with White men (Yang and Davis, 1988b; Corley and Buffler, 2001; Vizcaino et al, 2002; Kubo and Corley, 2004; Wu et al, 2006; Cook et al, 2009). Our study found a higher incidence of upper and middle oesophageal cancer in Black Caribbean men, but a lower incidence in Black African men compared with White men. Our study also found that White men had a higher incidence of lower oesophageal and gastric cardia cancers, which supports findings of previous studies in the United States and in the United Kingdom (Yang and Davis, 1988a, b; Corley and Buffler, 2001; El-Serag et al, 2002; Vizcaino et al, 2002; Kubo and Corley, 2004; Cook et al, 2009; Cooper et al, 2009; Hongo et al, 2009; Wu et al, 2006, 2009).

This national study included a large number of patients over a 7year period. Therefore, it was possible to investigate the variation in incidence between more specific ethnic groups and different subgroups of these cancers than analysed in previous national studies. This study also benefits from extracting self-assigned ethnicity for the majority of patient records (83\%). A recent study found that the completeness of case ascertainment in English cancer registries is high, using a method that identifies potentially missed cancer registrations from the HES dataset (Moller et al, 2011). Using this method, the completeness of oesophageal and gastric cancer registrations was estimated to be over $99 \%$ in 2008 (data not shown).

One limitation was that it was not possible to adjust for known risk factors, including socio-economic deprivation. However, as White individuals are less likely to live in the most deprived areas compared with the other ethnic groups studied (Tinsley and

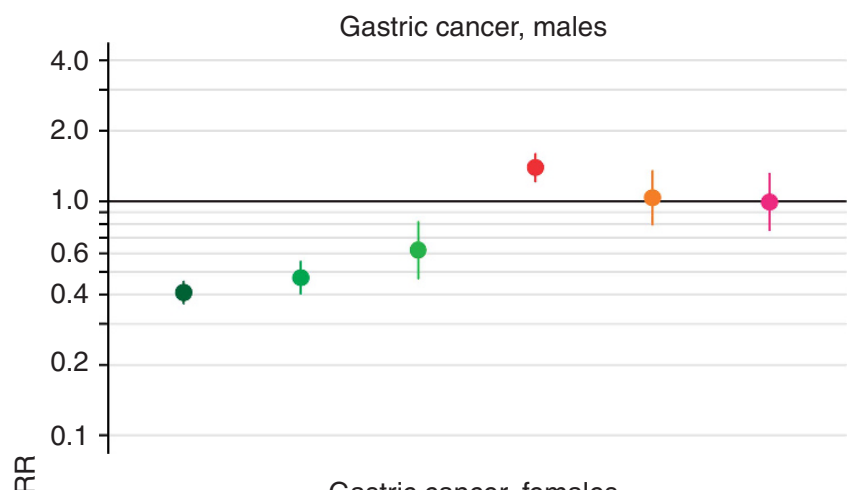

$\stackrel{\dddot{\Upsilon}}{\cong}$

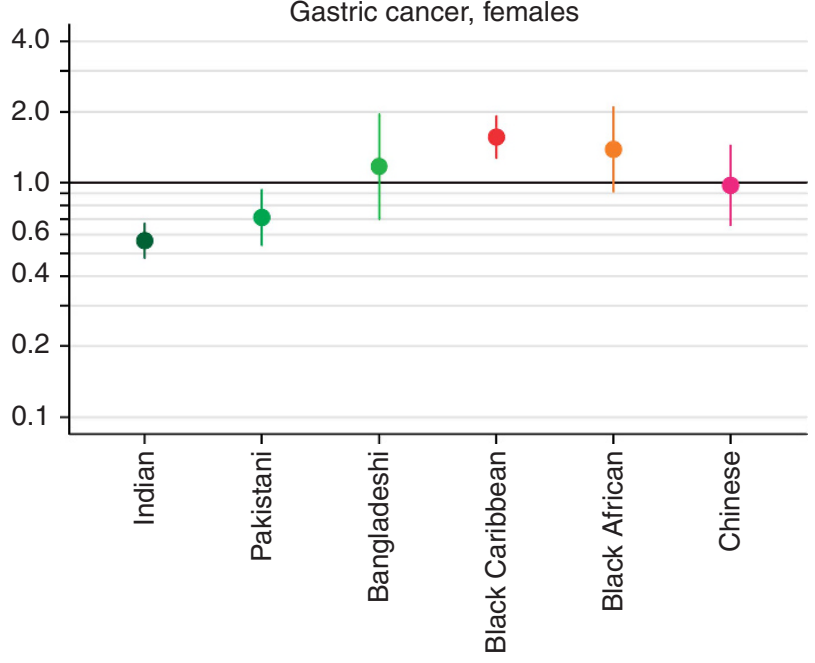

Figure 2 Age-standardised IRRs for men and women diagnosed with gastric cancer in England between 2001 and 2007 by ethnic group. White men and women used as references.

Jacobs, 2006) and because the incidence of both oesophageal and gastric cancer is higher in more deprived areas (National Cancer Intelligence Network, 2008), the effect of adjusting for deprivation would reduce the IRRs. This would strengthen some of the differences, in particular, the predominance of lower oesophageal and gastric cardia cancer in White males, but could lead to findings such as the higher incidence of upper and middle oesophageal cancer among Bangladeshi women being attenuated, resulting in a similar or lower incidence when compared with White women.

Around $17 \%$ of patients had no known ethnicity so agestandardised rates could not be presented. A sensitivity analysis, using an extreme assumption that all patients with an unknown ethnicity were actually White, found that our results were slightly attenuated, but that there was no material difference in our overall findings (data not shown). However, this extreme assumption will have misclassified some patients from other ethnic groups.

Over half $(51.9 \%)$ of gastric cancer patients were NOS, which meant they could not be assigned to either the cardia or non-cardia subgroup. Also, even after reassigning patients in the oesophageal NOS group to either the upper and middle or lower oesophageal groups based on their morphology, $11.6 \%$ of cases were still classified as NOS. However, these oesophageal subgroups made better use of all available coding, with a sensitivity analysis showing that defining subgroups based on morphology alone left a higher proportion (16.0\%) of cases classified as 'other and unspecified'. The sensitivity analysis found that the lower oesophageal and adenocarcinoma subgroups, the upper and middle oesophageal and squamous cell carcinoma subgroups, 

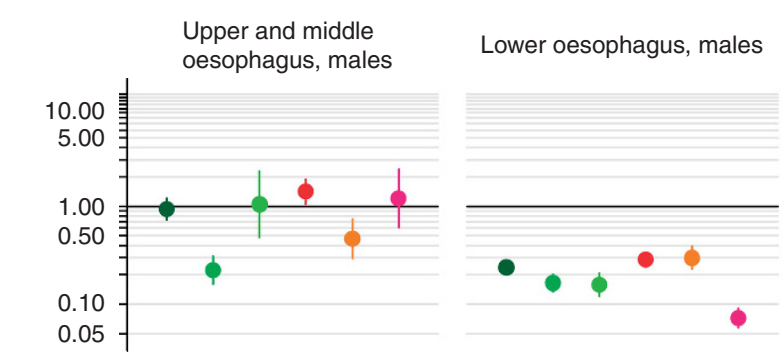

Oesophagus NOS, males
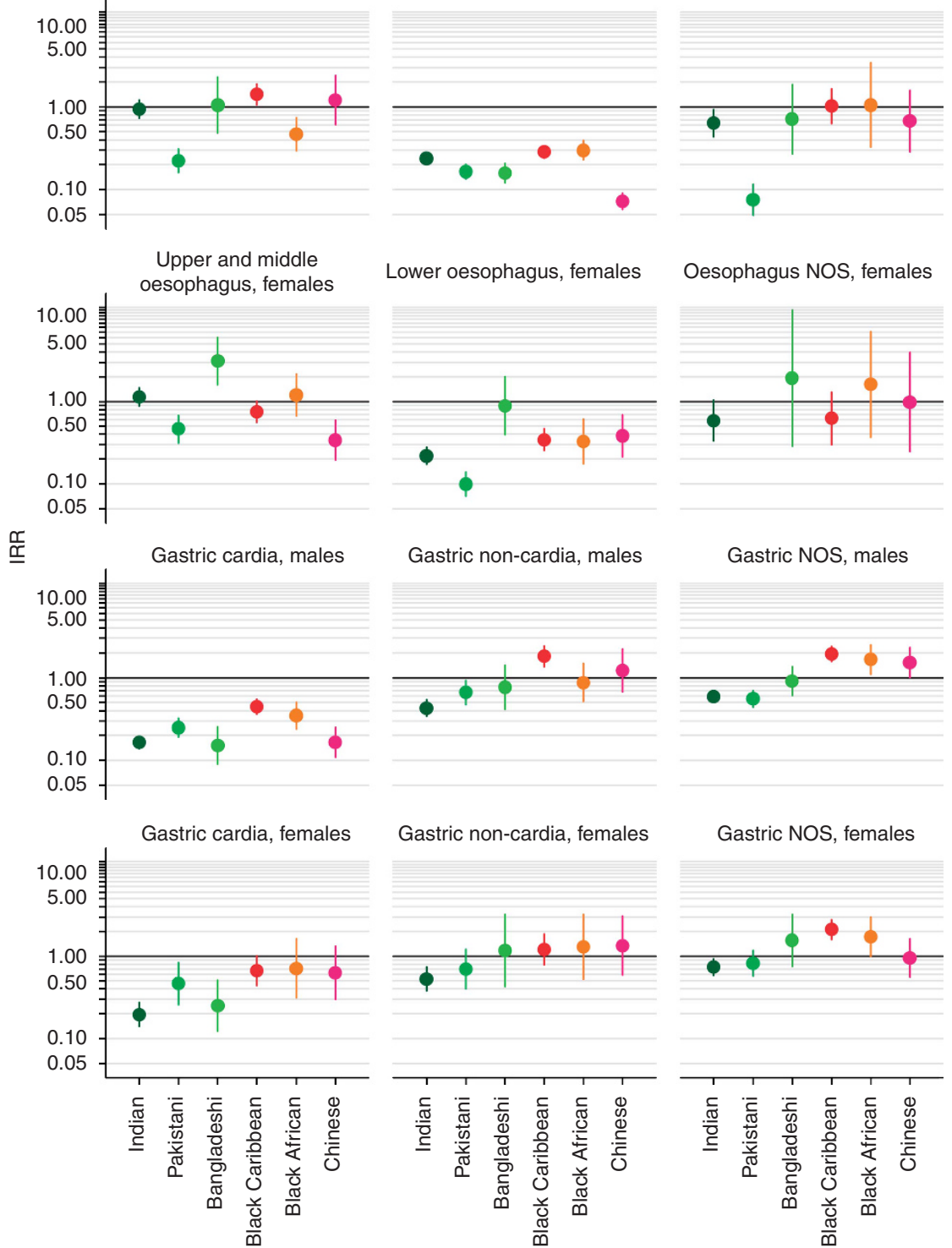

Figure 3 Age-standardised IRRs for men and women diagnosed with oesophageal or gastric cancer in England between $200 \mathrm{I}$ and 2007 by ethnic group and subgroup. White men and women used as references.

and the oesophageal NOS and 'other and unspecified' subgroups had very similar patterns in incidence between ethnic groups.

There was no information on country of birth, age at migration, or length of time in England, which may be important in terms of exposure to some early environmental risk factors. In the absence of information on patients' migration history, age could be used as a proxy, but because of the small number of cases in some specific age and ethnic groups, it was not possible to investigate variation in incidence by age. However, there was variation in the age distribution of individuals in ethnic groups. The highest median age was in the White group at 73 years. For the other ethnic groups studied the median age ranged from 63 years for the Chinese group to 71 years for the Black Caribbean group.

Oesophageal and gastric cancer subgroups are associated with different risk factors, although our understanding of the aetiology of some of these subgroups is uncertain (Blot et al, 2006). Tobacco smoking and high alcohol consumption are the main risk factors for squamous cell carcinoma of the oesophagus (Blot et al, 2006;
Shibata and Parsonnet, 2006; Lagergren and Lagergren, 2010). One possible explanation for the lower incidence of upper and middle oesophageal cancer in some ethnic groups could be a lower prevalence of smoking or alcohol consumption compared with the general population. However, this does not explain why some groups smoke and drink less than the general population (Sproston and Mindell, 2006), but have a similar incidence of this cancer compared with the White group.

Chewing areca nut (also known as betel quid when it is chewed with a betel leaf) both with and without chewing tobacco has been associated with an increased risk of developing oesophageal squamous cell carcinoma (Wu et al, 2001b; Akhtar et al, 2012). In 2004, around $16 \%$ of Bangladeshi women in England reported that they chewed tobacco including betel quid, a higher proportion than Indian (1\%) and Pakistani women (1\%) in the survey (Sproston and Mindell, 2006). This may possibly explain the higher incidence of upper and middle oesophageal cancer in Bangladeshi women. 
Barrett's oesophagus, chronic gastro-oesophageal reflux disease, and increasing body mass index are associated with an increased risk of developing oesophageal adenocarcinoma (Lagergren et al, 1999a, b, 2000; Wu et al, 2001a; Hampel et al, 2005; Crew and Neugut, 2006; Merry et al, 2007; El-Serag, 2008; Wood and Yang, 2008; Lagergren and Lagergren, 2010). A UK study found that White individuals had a higher risk of developing Barrett's oesophagus compared with South Asians and Afro-Caribbeans (Ford et al, 2005). Also, in 2004 the male general population were typically more likely to be overweight or obese compared with Indian, Pakistani, Bangladeshi, and Chinese men, whereas Black African and Black Caribbean men had a similar level of obesity (Sproston and Mindell, 2006).

Although infection with the most common strain $(\mathrm{CagA}+)$ of Helicobacter pylori has been established as a risk factor for non-cardia gastric cancer (International Agency for Research on Cancer, 1994), meta-analyses have found that such infection may be associated with a reduced risk of oesophageal adenocarcinoma and possibly gastric cardia cancer (Blot et al, 2006; Kamangar et al, 2006; Rokkas et al, 2007; Islami and Kamangar, 2008). Studies in the United States have found $H$. pylori infection to be lower in White compared with Black individuals (Taylor and Blaser, 1991; Everhart et al, 2000), which was partly explained by socio-economic factors such as lower income (Everhart et al, 2000). No population-wide studies investigating differences in the prevalence of $H$. pylori infection between ethnic groups have been reported in England. However, it is plausible that differences in H. pylori infection and socio-economic factors between ethnic groups could partly explain some of the observed variation in the incidence of these cancers.

Our study highlights the importance of investigating variation in incidence between more specific ethnic groups in subgroups of oesophageal and gastric cancer. There were differences in the

\section{REFERENCES}

Akhtar S, Sheikh AA, Qureshi HU (2012) Chewing areca nut, betel quid, oral snuff, cigarette smoking and the risk of oesophageal squamous-cell carcinoma in South Asians: a multicentre case-control study. Eur J Cancer 2012 48(5): 655-661

Ali R, Barnes I, Kan SW, Beral V (2010) Cancer incidence in British Indians and British whites in Leicester, 2001-2006. Br J Cancer 103(1): 143-148

Blot WJ, McLaughlin JK, Fraumeni Jr JF (2006) Esophageal cancer. In Cancer Epidemiology and Prevention, Schottenfeld D, Fraumeni Jr JF (eds). pp 697-706. Oxford University Press: New York

Boyle P, Parkin DM (1991) Statistical methods for registries. In Cancer Registration Principles and Methods, Jensen OM, Parkin DM, MacLennan R, Muir CS, Skeet RG (eds). pp 126-158. International Agency for Research on Cancer: Lyon

Cook MB, Chow WH, Devesa SS (2009) Oesophageal cancer incidence in the United States by race, sex, and histologic type. Br J Cancer 101(5): 855-859

Cooper SC, Day R, Brooks C, Livings C, Thomson CS, Trudgill NJ (2009) The influence of deprivation and ethnicity on the incidence of esophageal cancer in England. Cancer Causes Control 20(8): 1459-1467

Corley DA, Buffler PA (2001) Oesophageal and gastric cardia adenocarcinomas: analysis of regional variation using the cancer incidence in five continents database. Int J Epidemiol 30(6): 1415-1425

Coupland VH, Allum W, Blazeby JM, Mendall MA, Hardwick RH, Linklater KM, Møller H, Davies EA (2012) Incidence and survival of oesophageal and gastric cancer in England between 1998 and 2007, a populationbased study. BMC Cancer 12: 11

Crew KD, Neugut AI (2006) Epidemiology of gastric cancer. World J Gastroenterol 12(3): 354-362

Curado MP, Edwards B, Shin HR, Storm H, Ferlay J, Heanue M, Boyle P (2007) Cancer Incidence in Five Continents Vol IX. IARC: Lyon

Department of Health (2001) Guidance on Commissioning Cancer Services: Improving Outcomes in Upper Gastro-intestinal Cancers: The Manual. Department of Health: London incidence of these cancers between specific ethnic groups in England. Different patterns were also seen in the cancer subgroups. Differences in exposures to risk factors between ethnic groups might contribute to this variation. However, there are relatively few studies that investigate these factors in ethnic groups in England, which could help to elucidate why the observed variation in incidence exists.

\section{ACKNOWLEDGEMENTS}

This paper is a contribution from the National Cancer Intelligence Network and is based on the information collected and quality assured by the regional cancer registries in England (www.ukacr. org; www.ncin.org.uk). This work was carried out by the Thames Cancer Registry, King's College London, which receives funding from the Department of Health. The research was supported by the National Institute for Health Research (NIHR) Biomedical Research Centre based at Guy's and St Thomas' NHS Foundation Trust and King's College London. Victoria H Coupland also received funding through a King's College London postgraduate studentship.

\section{Conflict of interest}

The authors declare no conflict of interest.

\section{Disclaimer}

The views expressed are those of the author(s) and not necessarily those of the NHS, the NIHR or the Department of Health.
El-Serag HB (2008) Role of obesity in GORD-related disorders. Gut 57(3): 281-284

El-Serag HB, Mason AC, Petersen N, Key CR (2002) Epidemiological differences between adenocarcinoma of the oesophagus and adenocarcinoma of the gastric cardia in the USA. Gut 50(3): 368-372

Everhart JE, Kruszon-Moran D, Perez-Perez GI, Tralka TS, McQuillan G (2000) Seroprevalence and ethnic differences in Helicobacter pylori infection among adults in the United States. J Infect Dis 181(4): 1359-1363

Ford AC, Forman D, Reynolds PD, Cooper BT, Moayyedi P (2005) Ethnicity, gender, and socioeconomic status as risk factors for esophagitis and Barrett's esophagus. Am J Epidemiol 162(5): 454-460

Goggins WB, Wong G (2009) Cancer among Asian Indians/Pakistanis living in the United States: low incidence and generally above average survival. Cancer Causes Control 20(5): 635-643

Hampel H, Abraham NS, El-Serag HB (2005) Meta-analysis: obesity and the risk for gastroesophageal reflux disease and its complications. Ann Intern Med 143(3): 199-211

Hongo M, Nagasaki Y, Shoji T (2009) Epidemiology of esophageal cancer: orient to occident. Effects of chronology, geography and ethnicity. J Gastroenterol Hepatol 24(5): 729-735

International Agency for Research on Cancer (1994) IARC Monographs on the Evaluation of Carcinogenic Risks to Humans; (Volume 61; Schistosomes, Liver Flukes and Helicobacter pylori). IARC: France

Islami F, Kamangar F (2008) Helicobacter pylori and esophageal cancer risk: a meta-analysis. Cancer Prev Res 1(5): 329-338

Kamangar F, Dawsey SM, Blaser MJ, Perez-Perez GI, Pietinen P, Newschaffer CJ, Abnet CC, Albanes D, Virtamo J, Taylor PR (2006) Opposing risks of gastric cardia and noncardia gastric adenocarcinomas associated with Helicobacter pylori seropositivity. J Natl Cancer Inst 98(20): 1445-1452

Kubo A, Corley DA (2004) Marked multi-ethnic variation of esophageal and gastric cardia carcinomas within the United States. Am J Gastroenterol 99(4): 582-588 
Lagergren J, Bergstrom R, Lindgren A, Nyren O (1999a) Symptomatic gastroesophageal reflux as a risk factor for esophageal adenocarcinoma. $N$ Engl J Med 340(11): 825-831

Lagergren J, Bergstrom R, Nyren O (1999b) Association between body mass and adenocarcinoma of the esophagus and gastric cardia. Ann Intern Med 130(11): 883-890

Lagergren J, Lagergren P (2010) Clinical review: oesophageal cancer. $\mathrm{Br}$ Med J 341: 1207-1211

Lagergren J, Ye W, Bergstrom R, Nyren O (2000) Utility of endoscopic screening for upper gastrointestinal adenocarcinoma. JAMA 284(8): 961-962

Merry AH, Schouten LJ, Goldbohm RA, van den Brandt PA (2007) Body mass index, height and risk of adenocarcinoma of the oesophagus and gastric cardia: a prospective cohort study. Gut 56(11): 1503-1511

Møller H, Richards S, Hanchett N, Riaz SP, Lüchtenborg M, Holmberg L, Robinson D (2011) Completeness of case ascertainment and survival time error in English cancer registries: impact on 1-year survival estimates. Br J Cancer 105(1): 170-176

National Cancer Intelligence Network (2008) Cancer Incidence by Deprivation, England. 1995-2004. NCIN: UK

National Cancer Intelligence Network (2009) Cancer Incidence and Survival, by Major Ethnic Group, England, 2002-2006. NCIN: UK

National Cancer Intelligence Network (2011) Merged English Cancer Registry Data. http://ncin.org.uk/collecting_and_using_data/national_cancer_data_ repository/cancer_registry.aspx (last accessed: 13 August 2012)

Office for National Statistics (2011) Population Estimates by Ethnic Group: Methodology Paper. http://www.ons.gov.uk/ons/taxonomy/index.html? nscl=Population + Estimates + by + Ethnic + Group (last accessed: 2 October 2012)

Pohl H, Welch HG (2005) The role of overdiagnosis and reclassification in the marked increase of esophageal adenocarcinoma incidence. J Natl Cancer Inst 97(2): 142-146

Rokkas T, Pistiolas D, Sechopoulos P, Robotis I, Margantinis G (2007) Relationship between Helicobacter pylori infection and esophageal neoplasia: a meta-analysis. Clin Gastroenterol Hepatol 5(12): 1413-1417
Shibata A, Parsonnet J (2006) Stomach cancer. In Cancer Epidemiology and Prevention, Schottenfeld D, Fraumeni Jr JF (eds). pp 707-720. Oxford University Press: New York

Sproston K, Mindell J (2006) Health Survey for England 2004: The Health of Minority Ethnic Groups. The Information Centre: Leeds

Taylor DN, Blaser MJ (1991) The epidemiology of Helicobacter pylori infection. Epidemiol Rev 13: 42-59

Tinsley J, Jacobs M (2006) Deprivation and ethnicity in England: a regional perspective. Reg Trends 39: 19-28

Vizcaino AP, Moreno V, Lambert R, Parkin DM (2002) Time trends incidence of both major histologic types of esophageal carcinomas in selected countries, 1973-1995. Int J Cancer 99(6): 860-868

Wood RK, Yang Y-X (2008) Barrett's esophagus in 2008: an update. Keio J Med 57(3): 132-138

Wu AH, Wan P, Bernstein L (2001a) A multiethnic population-based study of smoking, alcohol and body size and risk of adenocarcinomas of the stomach and esophagus (United States). Cancer Causes Control 12(8): 721-732

Wu H, Rusiecki JA, Zhu K, Potter J, Devesa SS (2009) Stomach carcinoma incidence patterns in the United States by histologic type and anatomic site. Cancer Epidemiol Biomarkers Prev 18(7): 1945-1952

Wu MT, Lee YC, Chen CJ, Yang PW, Lee CJ, Wu DC, Hsu HK, Ho CK, Kao EL, Lee JM (2001b) Risk of betel chewing for oesophageal cancer in Taiwan. Br J Cancer 85(5): 658-660

Wu X, Chen VW, Ruiz B, Andrews P, Su LJ, Correa P (2006) Incidence of esophageal and gastric carcinomas among American Asians/Pacific Islanders, whites, and blacks: subsite and histology differences. Cancer 106(3): 683-692

Yang PC, Davis S (1988a) Epidemiological characteristics of adenocarcinoma of the gastric cardia and distal stomach in the United States, 1973-1982. Int J Epidemiol 17(2): 293-297

Yang PC, Davis S (1988b) Incidence of cancer of the esophagus in the US by histologic type. Cancer 61(3): 612-617

This work is published under the standard license to publish agreement. After 12 months the work will become freely available and the license terms will switch to a Creative Commons Attribution-NonCommercial-Share Alike 3.0 Unported License. 